\title{
La izquierda nacional en el suplemento de cultura de La Prensa (1951-1955)
}

\author{
The national left in the supplement of culture \\ of La Prensa (1951-1955)
}

\section{Pablo Adrián Vázquez}

pabloadrianvazquez@hotmail.com

http://orcid.org/0000-0002-6284-8301

Institutos Nacionales Eva Perón y Juan Manuel de Rosas

Universidad de Ciencias Empresariales y Sociales

Argentina

\section{Resumen}

En este trabajo el autor analiza el derrotero del suplemento cultural del diario La Prensa (1951-1955), centrándose en aquellos artículos escritos por los representantes de la llamada «izquierda nacional», en cuanto a su vinculación política con el peronismo. En la publicación colaboró un amplio elenco de periodistas, escritores e intelectuales, desde viejos «martinfierristas» y del núcleo literario «Boedo», hasta nacionalistas de cuño revisionista. Sobre esta premisa, el autor examina la influencia de dichos textos durante el primer peronismo y como gravitaron en el mundo cultural de su época.

Palabras clave

peronismo, socialismo, periodismo, La Prensa

\section{Abstract}

This essay analyses the trajectory of La Prensa newspaper's cultural supplement (1951-1955), with a focus on those articles written by supporters of the so-called «national left», regarding their political links with Peronism. Contributors included a wide range of journalists, writers and intellectuals, from old «Martinfierristas» and members of the literary group «Boedo», to nationalists of a revisionist stance. Building upon these grounds, the essay examines the influence exerted by the aforementioned texts during the first Peronism, and how they gravitated in the cultural world of their age.

Keywords

peronism, socialism, journalism, La Prensa 


\section{La izquierda nacional en el suplemento de cultura de La Prensa (1951-1955)}

\section{Por Adrián Vázquez}

En este trabajo se analizan los artículos publicados en el suplemento cultural del diario La Prensa, entre 1951 y 1955, cuya autoría pertenece a los referentes de la izquierda nacional de ese periodo histórico. El estudio se profundiza a partir de la vinculación de los autores con el sistema cultural del primer peronismo y de su correspondencia con las disputas y las tensiones de ese momento en nuestro país.

Aunque existió la idea general de que los periodistas y los escritores de la época debían tener una comprobable filiación peronista, o al menos ser cercanos al oficialismo, en el suplemento colaboró un amplio elenco de intelectuales de diversas procedencias ideológicas y fue notable la participación de autores de formación marxista y de representantes del futuro Partido Socialista de la Revolución Nacional (PSRN).

A partir de considerar al periódico como un «actor político colectivo» (Borrat, 1989, p. 5) que tiene por objetivo lucrar e influir con una ideología determinada, explícita o no, a fin de gravitar en la comunidad donde actúa en su beneficio, la producción de estos referentes de la izquierda nacional cumple un rol fundamental al explicitar su pensamiento y su producción intelectual. Por ello, se analizarán los aportes sobre historia y ciencias sociales que se difundieron en dicho suplemento, en cuanto a su orientación historiográfica, además de puntualizar en el rol de sus autores y en el lugar que ocupaban con respecto al oficialismo y al mundo cultural de la época.

\section{Izquierda nacional y peronismo}

El surgimiento del peronismo, tras el 17 de octubre de 1945, encontró divido al sector de la izquierda argentina. En el caso de los partidos Socialista y Comunista, la postura oficial de ambos fue la condena al nuevo movimiento por su filiación «nazifascita». Sin embargo, otro sector, deudor de las experiencias del Grupo Obrero Revolucionario 
(GOR), liderado por Liborio Justo (Quebracho), con sus órganos periodísticos La Internacional y - tras la ruptura con Reynaldo Frigerio (Lagos) - La Nueva Internacional, tuvo capital importancia en el origen de la izquierda nacional.

A las reducidas huestes de Liborio — una docena de personas - se suma [un] empleado en el sindicato textil: conocido bajo el seudónimo de «Irlan», su verdadero nombre es Adolfo Perelman. Precisamente, en esa época, Perelman traba contacto con un grupo de estudiantes secundarios de tendencia anarquista que publican la revista AES (Asociación de Estudiantes Secundarios) y logra arrancarlos del influjo de Bakunin para convertirlos a ese incipiente socialismo nacional que se expresa en el GOR. [...] se encuentran Enrique Rivera, de importante labor teórica posterior, y un «pelirrojo» que utiliza el seudónimo «Sevignac» y cuyo verdadero nombre es Jorge Abelardo Ramos. A menos de un año, Perelman y «sus muchachos» rompen con Liborio y pasan a constituir el grupo VOL (Vanguardia Obrera Leninista) [...]. Con Liborio quedan Matteo Fossa, Miguel Medunich Orza [...] y unos pocos más, nucleados ahora bajo la sigla LOR (Liga Obrera Revolucionaria) y editando el periódico Lucha Obrera (Galasso, 1983, p. 34).

En el marco de la reorientación que tuvo el periódico La Prensa al pasar a manos de la Confederación General del Trabajo (CGT), en 1951, fue lógico esperar un cambio en los parámetros ideológicos del tradicional diario del patriciado.

El oficialismo sostenía que el citado periódico era una empresa ligada al capital extranjero y, por tanto, vocera de intereses oligárquicos y antinacionales, y la oposición radical entendía que la clausura del mismo era un atentado del gobierno a la libertad de prensa. La participación de Cooke (en el debate parlamentario para justificar su expropiación) fue de trascendencia puesto que al refutar con sólidos argumentos lo que expusieron sus adversarios, le brindó a su bancada el sustento ideológico necesario para superar con ello el nivel general del debate (Panella, 1999, p. 5).

Desde la sección segunda de La Prensa se difundieron los temas culturales y el encargado de conducirla fue César Tiempo. Nacido en Ucrania, su primer libro, Versos de una... (1926), lo publicó bajo el nombre de Clara Beter y contó con el prólogo de Elías Castelnuovo. Con su poemario de 1930, Libro para la pausa del sábado, obtuvo el primer 
premio municipal de poesía de Buenos Aires. Le siguieron otras publicaciones de poemas, prosa y obras de teatro. Fue partícipe de la movida literaria de las primeras décadas del siglo XX entre los grupos de Florida y de Boedo, y se relacionó con los integrantes de la revista literaria Martín Fierro, como Raúl Scalabrini Ortíz y Jorge Luis Borges. Como periodista trabajó en los periódicos Crítica, La Época y Clarín, así como en la revista de arte Continente. Tiempo intentó dotar a la sección de amplitud de criterios y de estilos, pero imprimiendo un fuerte contenido costumbrista junto con temáticas más universales.

Mención especial merece Pablo Carvallo (seudónimo de Jorge Abelardo Ramos), ${ }^{1}$ referente máximo de la izquierda nacional, que fue quien más publicó textos sobre historia y temática universal en dicho suplemento. Y más destacada, por su rareza, fue la nota «La continuidad histórica» (sobre la Edad Media), del jurista y exdiputado Enrique Dickmann, ${ }^{2}$ quien en esos años fue expulsado del Partido Socialista por su acercamiento a Juan Perón.

\section{Historia: entre el legado liberal y la impronta revisionista popular}

En comparación con las otras temáticas, la historiografía tuvo un espacio reducido, pero lograron visibilizarse en parte las tensiones historiográficas de la época, en un intento por superar la visión «mitrista» pero con el planteo de un «revisionismo» más federalista y menos centrado en Rosas, a la vez que poco se insinúa la visión de la Nueva Escuela Histórica de Levene.

Los nombres de historiadores reconocidos fueron escasos en comparación con poetas y con narradores. La historia se refugió en el espacio «Comentarios de Libros», en las columnas sobre «Nacionalidad y Estirpe», en «Estampa del Pasado» y en notas sin firma sobre el aniversario de algunas fundaciones de provincia o de ciudades argentinas. La línea oficialista se explicitó en notas laudatorias sin firma sobre los avances del gobierno, amén de la extensa cobertura por el fallecimiento de Eva Perón, el 26 de julio de 1952, de algún acto proselitista por el 1 de mayo y el 17 de octubre, y de noticias sobre el mundo sindical. 
Entre aquellos autores con base académica y sentido de investigación historiográfico se puede destacar, en la línea liberal, a Arturo Capdevilla ${ }^{3}$ y a Carlos G. Romero Sosa, ${ }^{4}$ y en el revisionismo, a José María Rosa ${ }^{5}$ — con el seudónimo Martín Pincel—, a José Luis Muñoz Azpiri ${ }^{6}$ y a Fermín Chávez. ${ }^{7}$ Fue paradigmático que Rosa tuviese que escribir con seudónimo. Como él mismo indica:

Tenía un nombre demasiado nacionalista para que conviniera. Ni me lo pidieron ni me hubieran publicado nada. Pero ahora recuerdo; cuando se entregó La Prensa a la CGT, Bonato me pidió que colaborara en la sección literaria que dirigía César Tiempo. Como mi nombre tenía resonancia nacionalista, firmé con mi seudónimo, Martín Pincen (Hernández, 2008, p. 127).

Sus aportes fueron variados, aunque circunscriptos al período 1951-1952. Tal es el caso de «Pincén, el indómito», «Los constituyentes en Santa Fe» y «La defensa de la nacionalidad en La razón de mi vida».

En materia de derecho se destacaron los artículos de Lucio M. Moreno Quintana («El legado de España al derecho internacional», «¿Qué es el derecho internacional?», «El tercer estado del derecho internacional» y «La guerra total») y de Arturo Sampay, ${ }^{8}$ jurista de filiación católica y peronista que tuvo el pulso de un historiador profesional para los artículos publicados en La Prensa («Una ley política de Aristóteles con actualidad nacional» $\mathrm{y}$ «Los principios constitucionales de un nuevo Código Civil Argentino»).

\section{Entre las tradiciones telúricas,}

la historia local y la internacional

Hubo autores que acentuaron la publicación de trabajos sobre caudillos federales (muchos antirosistas), sobre tradiciones telúricas y sobre costumbrismo de sus provincias. Entre ellos, Nicanor Alurralde, Ignacio Camps, Luis Farre y Juan Carlos Dávalos. En esta línea, se destacaron los artículos del riojano Luis Fernández Zárate sobre el «Chacho» Peñaloza y la historia de La Rioja. 
Fermín Chávez referenció la historia de López Jordán, y sus añoranzas de Nogoyá y «El Pueblito», en «Voces y creencias de Entre Ríos» y, en la línea de unir la cuestión histórica con la poética y la heredad del terruño entrerriano, publica sobre Olegario V. Andrade «¿Es de Andrade el folleto Las dos políticas?».

Desde el pulso periodístico, Juan Rómulo Fernández y Oscar Ferri se refirieron a distintos sucesos de la historia nacional en entono más ensayístico y anecdótico, sobretodo mediante el rescate de la figura de Domingo F. Sarmiento. A modo de ejemplo, se pueden apreciar las palabras de Juan R. Fernández sobre el contenido testamentario dejado por Sarmiento.

Con respecto a historia americana hubo pocos textos. Se destacan los de Arturo Céspedes, «Nietzsche y el mariscal Solano López», «Ezequiel Koremblit. A 200 años del nacimiento de Hidalgo, revolucionario mejicano y héroe de América», «Carlos Marin. Introducción de los negros en la época de la conquista», y del propio César Tiempo (seudónimo de Israel Zeitlin), «Martí, el Quijote de la Manigua».

Sobre temas de historia europea y universal hubo colaboraciones de autores españoles. Tal es caso de Roberto Riber, con su nota «Las batallas del Bruch»; de Eugenio d' Ors, ${ }^{9}$ con «Leonardo Da Vinci arquitecto» y «El tiovivo de los historiadores»; y del italiano Salvatore Di Vito, con su texto «El banco más antiguo del mundo».

En cuanto a notas y textos que fluctúan entre el reconocimiento a la cultura nativa, la poética criollista y la semblanza, se destacan: Cátulo Castillo, ${ }^{10}$ Carlos De Jovellanos y Paseyro, Jorge Sourigues, Enrique Stieben, ${ }^{11}$ Héctor Villanueva, ${ }^{12}$ Francisco Muñoz Azpiri ${ }^{13}$ y Enrique Pavón Pereyra. ${ }^{14}$

\section{Izquierda nacional, política y revisionismo}

Los representantes de la izquierda nacional que ya publicaban durante el primer peronismo algunos artículos esporádicos en revistas como Hechos e Ideas, tuvieron una presencia más fuerte en el suplemento liderado por Tiempo. En prosa o en verso, en notas históricas o de arte, las colaboraciones fueron variadas. 
Eduardo Astesano publicó «Una historia del alambrado» (31/1/1954). Juan Unamuno, «Proyecciones de la visita» (5/6/1953), sobre el encuentro entre Perón e Ibánez del Campo en perspectiva del acuerdo del ABC. Alfredo Muzzopappa, «Ubicación social del existencialismo» (1/6/1952), «Vida y pasión de la cultura argentina» (29/6/1952), «Argentina y Chile. El sentido del retorno» (5/7/1953), «El heroísmo popular de octubre» (16/10/1953), «Existencialismo: inmolación de la voluntad» (26/4/1953) y «Agustín Álvarez. Precursor de la crítica política» (21/2/1954). Amén de ellos, según Guillermo Korn (2013), el autor «pertenecía al cuerpo de editorialistas de La Prensa desde que pasó a manos de la CGT: había sido el traductor de textos sobre marxismo...» (p. 111).

Se destacan las notas del jurista y exdiputado Enrique Dickmann: «La discriminación racial» (27/9/1953); «La continuidad histórica» (31/5/1953), sobre la Edad Media, y «Sermón laico» (12/7/1953), donde explicita su matriz ideológica y preanuncia las líneas a seguir por el PSRN.

Mención especial merece Pablo Carvallo (seudónimo de Jorge Abelardo Ramos), ya que fue quien más publicó en dicho suplemento. Víctor Almagro fue el seudónimo que utilizó para editorializar en Democracia, así como Mambrú y Antídoto, entre otros, para otros medios de signo peronista. Escapando del recuerdo del secuestro de su libro, su nombre podía ser censurado, pero no su pluma.

Según Enzo Regali (2012), militante del Frente de Izquierda Popular (FIP) en los setenta, «Abelardo solía contar que fue candidato a dirigir dicho diario (La Prensa), pero Evita lo vetó» (p. 190).

Durante 1952 publicó: «Hugo y sus batallas póstumas» (9/3), «Weidle o la nostalgia de un mundo perdido» (16/3), «Actualidad de Nicolás Gogol» (23/3), «El extraño sobrino de Chateaubriand» (13/4), «Juventud y agonía del surrealismo» (27/4), «El hombre y la máquina» (11/5), «Cartas de Romain Rolland a Gandhi. Literatura y política» (8/6), «La herencia cultural y la clase trabajadora. El escritor y las fuerzas históricas» (22/6), «La crisis de un arte posible» (6/7), «El poeta como profeta. Valéry o la conciencia del fin» (13/7), «Historia y pavor. Sobre el auge de Arnold Toynbee» (20/7) y «Zola: el ingreso de la clase obrera en la literatura» (23/11).

Para 1953 solo serán tres textos: «Cuando la burguesía era joven. De los Medicis a los Rockefeller» (8/2), «El enigma chino y otros enigmas» (11/10) y «Proposiciones para un país inconcluso. De la balcanización a la unidad» (24/5). Trastoco el orden cronológico 
pues este último texto retoma su tesis expresada en la obra censurada América Latina, un país (1949), e incorpora el término balcanización, caro a sus textos posteriores, que se relaciona con el espíritu de sus artículos sobre política exterior en el diario Democracia y comparte temática con los textos de Descartes (seudónimo del propio Juan Perón).

Mención aparte amerita su análisis sobre la obra de Ernesto Sábato donde, si bien coincide en el análisis con el también heterodoxo izquierdista, difiere en sus conclusiones:

La historia no es una suma de catástrofes, es una tensión dramática entre diversos regímenes sociales en pugna, entre formas estéticas hostiles o crisis religiosas. No hubo un Renacimiento. Hubo varios y muchos crepúsculos acompañaron como una sombra a esas cimas del orgullo y el poder humanos. El aparente predominio de la máquina sobre el hombre no es otra cosa que la preeminencia del capital financiero sobre el mundo (Carvallo, 1953, p. 2).

El accionar del PSRN y sus artículos en Democracia lo llevaron a concentrarse en ellos y a dejar de lado su labor en La Prensa.

\section{A modo de conclusión}

Esta experiencia cultural demandó un notable esfuerzo a César Tiempo, ya que le cupo lidiar con el equilibrio de autores que marcaban nuevos rumbos, aquellos adherentes al régimen peronista y aquellos otros que no fueron justicialistas pero que no podían ser ignorados por su aporte intelectual.

Volví a Buenos Aires en 1951e hice periodismo en varios diarios hasta que en 1952 empecé a dirigir el suplemento de La Prensa que había sido absorbida por la CGT. Allí estuve hasta 1955. Me aguanté el resentimiento y el odio de todas las fuerzas liberales. Perón se dio el gusto de hacer un buen suplemento. No me obligaron a afiliarme, llevé como diagramador a un comunista. Publiqué a Quasimodo, a Neruda, a Gabriela Mistral, a Amaro Villanueva, que era candidato a gobernador de Entre Ríos por el Partido Comunista [...]. En aquel tiempo, en el peronismo estaba en onda un término para rechazar a la gente que no interesaba, «no corre», atribuido caprichosamente al General. A mí me 
parecía que era puro grupo, así que empecé a usar lo contrario, «corre por orden del general», y todo iba bien. A nadie se le ocurría preguntármelo. En esa época llegó mucha gente, obreros, sindicalistas, que traían poemas apologéticos a Perón para que se le publicaran, pero nunca los dejé correr, solamente por su falta de calidad (Toker, 1997, p. 17).

Su perfil fue de apoyo al oficialismo, de antemano con afinidad ideológica a nivel primario ante el proceso político de aquella época. Aunque no hubo posibilidad de que se incorporase algún escritor contrario al peronismo en dichas páginas.

También César Tiempo debió planear dicha sección como alternativa en una época en la que la oferta cultural fue numerosa, pero escasamente neutral con relación al peronismo. A la vez que tuvo que enfrentar el pasado liberal de La Prensa, con su impronta más cercana a Sur y a otras publicaciones similares, amén de su propia formación cultural que era ajena al revisionismo y al rosismo.

Para la visión de un sector de historiadores actuales,

los avances revisionistas, desde el punto de vista institucional, son éxitos a medias. Esto se hace evidente en lo que respecta a la educación, a la universidad y al mundo académico. Su éxito más tangible se sitúa en el plano de la divulgación, sobre todo en la medida en la que se benefician cada vez más del control de la prensa instaurado por el peronismo. Plumas revisionistas colaboran ampliamente en la prensa peronista, en los diarios Tribuna, El Líder, Democracia y en la revista Hechos e Ideas, así como en la experiencia de «nacionalización» del matutino La Prensa, expropiado en 1951 (QuattrocchiWoisson, 1999, p. 270).

La representación de las corrientes historiográficas buscó explicitar tanto la corriente oficial como al revisionismo de forma dosificada, mediante la publicación de trabajos académicos y de sentidas semblanzas de San Martín, de Belgrano, de Rivadavia y de Sarmiento con un tono más cercano al historicismo mitrista, por un lado, y de alguna referencia al revisionismo, a la historia de caudillos y a las referencias criollistas, por el otro. Fueron emblemáticas las menciones a Peñaloza y a López Jordán, al tiempo que fue notable la ausencia de menciones a Urquiza, a Mitre y a Roca. De igual forma, la mención a Juan Manuel de Rosas se realizó, casi como al pasar, en un par de artículos, al igual que a Martín Miguel de Güemes y a Martiniano Chilavert. 
Tarea difícil es analizar cuales fueron las reacciones del público receptor ante las interpelaciones de la segunda sección de La Prensa con relación a los artículos sobre historia. En principio, se planteó desde una perspectiva heterogénea, a fin de captar un público masivo de los sectores medios y obrero, de proyección nacional, con cierto conocimiento y contacto con la cultura.

Las esperanzas del sector revisionista - por el tenor y la cantidad de los artículosfueron cubiertas a medias. Fue más que emblemático que José María Rosa, el autor más popular de ese sector, tuviese que escribir con seudónimo, mientras que solo existió un texto explícito sobre Juan Manuel de Rosas a cargo de Muñoz Azpiri.

¿Fue ese suplemento un canal de comunicación orgánico de la «izquierda nacional» durante el primer peronismo? No, en principio, ya que la presencia de estos autores se dio por afinidad a César Tiempo y su propuesta periodística, amén de compartir espacios culturales afines, más que por una estrategia política de conjunto. Eso no quita que alguno de ellos lo haya utilizado o lo haya sentido de este modo. Es cierto, sin embargo, que la presencia de autores de izquierda, tanto argentinos como latinoamericanos —como Diego Rivera y Pablo Neruda—, fue constante y marcó un ámbito de pluralidad acotada o tolerada en esos años que no puede pasarse por alto.

Quizás este trabajo, y otros que le sigan, posibiliten rescatar el legado del suplemento cultural de La Prensa que, de la mano de César Tiempo y de una pléyade de autores, intentó reflejar la realidad cultural argentina, enmarcada en la política de Estado del primer peronismo, y cuya producción de sentido debe ser estudiada lejos del prejuicio y del sectarismo.

\section{Referencias}

BORRAT, H. (1989). El periódico, actor político. Barcelona, España: Gustavo Gili.

CARVALLO, P. (1953, 11 de mayo). El hombre y la máquina. La Prensa, segunda sección.

GALASSO, N. (1983). La izquierda nacional y el FIP. Buenos Aires, Argentina:

Centro Editor de América Latina. 
HERNÁNDEZ, P. (2008). Conversaciones con José María Rosa. Buenos Aires, Argentina: Fabro.

KORN, G. (2013). Hijos del pueblo. Entre «La Internacional» y «la Marcha». En Rein, R. y Panella, C. Cultura para todos. El suplemento cultural de La Prensa cegetista (1951-1955). Buenos Aires, Argentina: Biblioteca Nacional.

PANELLA, C. (1999). La Prensa y el Peronismo. Crítica, conflicto, expropiación. La Plata, Argentina: Ediciones de Periodismo y Comunicación.

REGALI, E. (2012). Abelardo Ramos: la izquierda nacional y la nación latinoamericana. Córdoba, Argentina: Ferreyra Editor, Ediciones de Corredor Austral y Ciccus.

QUATROCCHI-WOISSON, D. (1999). Los males de la memoria. Historia y política en la Argentina. Buenos Aires, Argentina: Emecé.

TOKER, E. (1997). Buenos Aires, esquina sábado. Antología de César Tiempo. Buenos Aires, Argentina: Archivo General de la Nación.

\section{Notas}

1 Jorge Abelardo Ramos (1921-1994). Político, historiador y escritor argentino, creador de la corriente política e ideológica llamada Izquierda Nacional, de notable influencia intelectual en Argentina, Uruguay, Bolivia y Chile. En 1961 fundó el Partido Socialista de la Izquierda Nacional (PSIN), desde el cual impulsó, en 1971, el Frente de Izquierda Popular (FIP). En las elecciones de septiembre de 1973, el FiP llevó en su boleta presidencial la fórmula Perón-Perón y logró 70o.ooo votos. Entre sus obras se destacan: Revolución y contrarrevolución en la Argentina (1957, cinco tomos), Ejército y semicolonia (1968), Historia de la nación latinoamericana (dos tomos) (1968), Historia del estalinismo en la Argentina (1969) y Adiós al coronel (1983).

2 Enrique Dickmann (1874-1955). En 1895 se naturalizó argentino y comenzó su militancia en el socialismo; dos años después asumió por primera vez la dirección de La Vanguardia. Médico egresado de la Universidad de Buenos Aires fue diputado nacional por Capital Federal en seis oportunidades entre 1914 y 1943. En 1952, luego de su expulsión del Partido Socialista, fundó el Partido Socialista de la Revolución Nacional en apoyo al rumbo del gobierno peronista. 
3 Arturo Capdevila (1889-1967). Poeta, autor dramático, docente y narrador. Fue miembro de la Academia Nacional de Historia. Entre sus obras se destacan: Jardines solos (1911), Velpámene (1912), El poema de Nenúfar (1915), El libro de la noche (1917); en teatro, Zincalí (1927); en novela, Arbaces, maestro de amor (1945); en sus evocaciones, Córdoba del recuerdo (1923); en cuentos, La ciudad de los sueños (1925); en escritos sobre temas idiomáticos, Babel y el castellano (1928); en temas históricos, Las invasiones inglesas (1938), Historia de Dorrego (1949), El hombre de Guayaquil (1950) y Nueva imagen de Juan Manuel de Rosas (1945).

${ }_{4}$ Carlos G. Romero Sosa (1916-2001). Historiador salteño, desempeñó cargos vinculados con los estudios históricos y el mundo de las bibliotecas, amén de ejercer la cátedra universitaria y de publicar valiosos estudios. Integró la Junta de Historia Eclesiástica Argentina.

5 José María Rosa (1906-1991). Historiador, abogado, político, docente y diplomático. Escribió El cóndor ciego (1952); Nos, los representantes del pueblo (1955); La caída de Rosas (1958); Del municipio indiano a la provincia argentina (1958), Rivadavia y el imperialismo financiero (1964); La Guerra del Paraguay y las montoneras argentinas (1965) y la colección Historia Argentina, de trece tomos, que luego de su muerte continuaron discípulos y colaboradores. Fue Presidente del Instituto Rosas y fundador de la revista Línea.

6 José Luis Muñoz Azpiri (1920-1976). Historiador, escritor y diplomático. Fue Miembro de número del Instituto Rosas. Escribió en numerosos periódicos y revistas, y en 1966 publicó Rosas frente al imperialismo inglés e Historia completa de las Malvinas, en tres volúmenes.

7 Fermín Chávez (1924-2006). Historiador, poeta y periodista. Cursó humanidades, filosofía y dedicó tres años a estudiar teología, derecho canónico y hebreo antiguo, en Cuzco. En 1950 conoció a Evita y se integró a su círculo de allegados. Después del Golpe de Estado de 1955 participó intensamente en «la Resistencia». En 1973 formó parte de la delegación que acompañó el regreso de Perón a la Argentina. Ocupó diversos cargos públicos durante los gobiernos justicialistas y fue profesor en las Universidades de Buenos Aires, de La Plata y de Lomas de Zamora. Publicó: Otra vuelta de Martín Fierro (1999), Siete escolios sobre Perón (2000) e Historia y antología de poesía gauchesca (2004). Escribió en Tribuna, El Líder, La Prensa, Democracia, La Capital (de Rosario), La Opinión, Mayoría y Clarín.

8 Arturo Enrique Sampay (1911-1977). Jurista, constitucionalista y docente. En 1933 escribió su primer libro, un estudio dedicado a la Constitución de la Provincia de Entre Ríos. En 1946 fue designado fiscal de la Provincia de Buenos Aires. Fue elegido convencional constituyente de la Convención que sancionó la Constitución Nacional de 1949. En 1951 publicó Introducción a la teoría del Estado, que tuvo reconocimiento internacional como uno de los estudios de derecho político más destacados del mundo. En 1952, por enfrentamiento internos en el peronismo, 
debió exiliarse en Uruguay. En 1968 fundó la revista Realidad Económica y en 1973 estuvo a cargo del Consejo Federal de Inversiones.

9 Eugeni d' Ors (1882-1954). Escritor e intelectual en lenguas catalana y castellana, fue el principal ideólogo del noucentisme, movimiento cultural con el que la burguesía catalana trató de impulsar su proyecto de construcción nacional a comienzos del siglo XX. Adhirió a los postulados falangistas y fue gran colaborador en lo cultural durante el régimen franquista.

10 Ovidio Cátulo González Castillo (1906-1975). Poeta, compositor, boxeador, docente, militante político y sindical. Fue autor, entre otros, de los tangos Organito de la tarde, El aguacero, Tinta Roja, Caserón de tejas, María y El último café. Fundador de SADAIC (Sociedad Argentina de Autores y Compositores de Música) y adherente al peronismo. En 1955 fue perseguido por la Revolución Libertadora, que lo incluyó en su lista negra y lo proscribió por ser militante peronista. Ya en los años sesenta forjó importantes éxitos con Troilo, y con Stamponi.

11 Enrique Stieben (1893-1958). Historiador y ensayista. Fue profesor normal, radicado en La Pampa, donde escribió sobre folclore, costumbres y geografía en muchos medios periodísticos.

12 Héctor Villanueva (1918-2003). Poeta y diplomático. Fue uno de los cabales representantes de la Generación del 40 e integrante, en 1950, de la Peña de Eva Perón. Entre sus obras se encuentran: De la espuma a la piedra (1942), Agradecimiento de las tardes (1944), Teoría de la araña (1957) y Los poemas de los árboles (1988).

13 Francisco Muñoz Azpiri (1915-1968). Periodista, libretista y escritor. Durante 1939 y 1940 dirigió la sección Letras del diario La Unión, de Lomas de Zamora, por entonces tercero en importancia en el periodismo bonaerense. Asomó a la vida pública en la década de 1940, cuando se acercó a Perón y a Evita. A esta como libretista. Desde junio de 1944 fue jefe de sección en Propaganda del Estado. Desde junio de 1950 fue vocal de la Comisión Nacional de Cultura y tuvo funciones en la Dirección General.

14 Enrique Pavón Pereyra (1921- 2004). Ensayista, periodista y escritor. Director del Museo de Perón en Lobos, Buenos Aires, y Director de la Biblioteca Nacional. Se destacó como biógrafo del Presidente Juan Perón, destacándose sus obras: Perón (1895-1942), publicada en 1953, Coloquios con Perón (1965), Yo Perón (1993), Vida de Perón (1965) y Perón, el hombre del destino (1974, cuatro tomos y un apéndice). 